\title{
German Inpatient Quality Indicators, Version 3.1
}

Standardized and comparable outcome measures are needed for the identification of quality problems and the management of improvements. The German Inpatient Quality Indicators (G-IQI) [1] provide a tool to measure volumes, medical outcome and other quality indicators in a comparable way based on available administrative data. The use of data generated in the DRG (Diagnosis Related Groups) billing process has important advantages:

The reference to DRG billing data reduces the risk of manipulations. Complications which are charged automatically become a subject of quality control, which is intended and provides a crosscheck for correctness of data.

- Cases cannot be omitted (unless they are not charged). Therefore, with respect to the cases included, the information is complete.

- The definition of indicators is standardized with respect to the coded information controlled on different levels in the reimbursement process.

- There is no additional effort for data collection.

- Results are available immediately after patient discharge.

The G-IQI system, which has been developed during the last ten years, has largely been extended in the new version 3.1 released in the year 2011. On the one hand indicators for some diseases and procedures, which had already been covered before, have been refined and complemented by adding new measures. On the other hand indicators for important diseases and procedures, which have not been covered before, were added.

Refinements include for example the share of ischemic stroke patients receiving thrombolytic therapy and the respective mortality of this subgroup. Furthermore the share of stroke patients receiving standardized stroke unit treatment is indicated. In case of myocardial infarction, the share of patients treated by a coronary catheter and/or coronary surgery is indicated. Thus besides mortality numbers some indicators have been added which inform about the use and/or effective availability of specific services considered to be related to better outcome.

New indicator groups cover, among others, the following diseases and procedures: cardiac surgery, thoracic surgery, peripheral vascular surgery, amputations, chronic obstructive pulmonary disease, geriatrics, spine procedures, gastric resections, cystectomy, etc.
The indicators mostly refer to measures which have been used in scientific investigations before (references are given in the G-IQI definition manual). Unlike more general indicator approaches which need more extensive risk adjustment, our indicators address specific diseases and/or procedures, which are stratified by risk groups. In case of peripheral artery procedures for example the indicators are differentiated by Fontaine classes and additional criteria. Besides providing more adequate outcome information such differentiation improves acceptance by physicians.

The new G-IQI are the most extensive quality indicator system based on available coded data. As these data are present in the information systems of hospitals, insurance companies and on a national level, the indicators can readily be applied. They enable hospitals to set up a continuous quality management process and to identify areas which might have quality problems. In conjunction with peer review (audit) procedures targeting such weaknesses these outcome oriented management processes have been shown to improve outcome significantly, especially in hospitals starting from subpar results.

G-IQI is currently used by about a quarter of the German hospitals on a voluntary basis for quality management. It has become the basis of the Swiss and the Austrian indicator system as presented elsewhere on this conference. G-IQI is necessarily (due to data availability) restricted to single case data. In cooperation with the AOK indicator systems have been developed which extend the scope beyond the single case to long term measurements using insurance data. In future both systems will be needed in parallel. Hospitals need G-IQI for rapid analysis and quality management. Results of long term indicators, which are available with delay only, will complement the short term indicators with more standardized measures and additional information on important issues of late outcome.

Autorenerklärung: Das Fachgebiet Strukturentwicklung und Qualitätsmanagement im Gesundheitswesen ist eine Stiftungsprofessur der Helios Kliniken GmbH.

Literatur

1 Mansky T, Nimptsch U, Winklmair C, Vogel K, Hellerhoff F. G-IQI | German Inpatient Quality Indicators Version 3.1. Berlin: Universitätsverlag der TU Berlin: 2011 URN: urn:nbn:de:kobv:83-opus-30042, URL: http:/ /opus.kobv.de/tuberlin/volltexte/2011/3004/
T. Mansky

Qualitätsmanagement

Keywords

quality indicators

administrative data

outcome

Schlüsselwörter

Qualitätsindikatoren

Routinedaten

Ergebnisqualität

Institut

Technische Universität Berlin, Berlin

Bibliografie

DOI 10.1055/s-0031-1286076 Dtsch Med Wochenschr 2011; 136: S47 - (c) Georg Thieme Verlag KG Stuttgart - New York . ISSN 0012-0472

Korrespondenz Prof. Dr. med. Thomas Mansky Technische Universität Berlin Fachgebiet Strukturentwicklung und Qualitätsmanagement im Gesundheitswesen Straße des 17. Juni 135 10632 Berlin

Tel. 030/314-29805 eMail thomas.mansky@ tu-berlin.de 